\title{
Survival of the Fittest
}

\section{The Evolution of the Children's Survival Novel}

PAULINE DEWAN

$\mathrm{S}$

urvival novels provide a host of attractions for children. On a continuum of danger, they are the high-risk counterparts of adventure narratives.

Characters in survival novels face not just adversity and risk, but also potential death. The fast pace and high drama of these narratives have always made them popular choices for children.

In his introduction to the 2009 Puffin Classic edition of The Swiss Family Robinson, renowned children's writer Jon Scieszka reminds us of their attractions, "Living in a giant tree house in a tropical jungle. Catching monkeys. Shooting sharks. Lassoing sea turtles. Exploring. Hunting. Fishing, Surviving. If you are not interested yet, you don't need to read any further." The exotic, remote, and extreme landscapes depicted in novels such as The Swiss Family Robinson may be a strong appeal for children unfamiliar with such places.

The protagonists who face life-threatening challenges do so largely without adult supervision. By confronting extreme situations on their own, they develop hardier, more resilient selves. Reading these novels, children can try out adult roles and experience vicariously what it would be like to be completely independent, in charge of their own decisions. Moreover, the lure of simplifying life, stripping down to essentials, and starting over in harmony with the natural world is hard to resist. Although survival stories were initially written for boys and began as stories of empire, ${ }^{2}$ they have changed dramaticallybecoming more inclusive in terms of gender, race, religion, and physical/mental ability, and exploring a range of issues that reflect the needs and interests of children today.

\section{Classic Survival Novels}

Daniel Defoe's Robinson Crusoe-the parent of the children's survival novel-laid the foundation for later authors. Published in 1719, it has been translated into

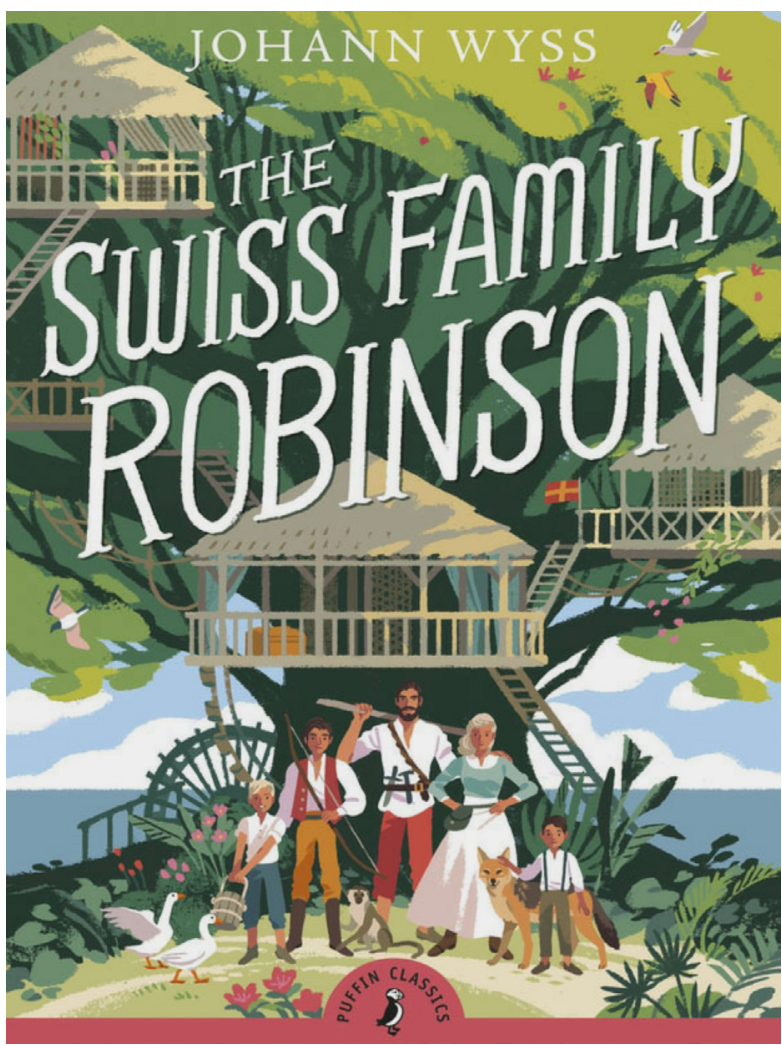

numerous languages, and has remained popular for three centuries. ${ }^{3}$ Although not written for children, it is a story that many of them are familiar with through comics, television, or other adapted/abridged versions. This prototype text established the motifs that the children's survival story has adopted in a variety of ways. A shipwreck strands a castaway who takes an initial inventory of his stock, salvages items from a shipwreck, finds and creates tools, builds a shelter, and later a second shelter on another part of the island. Eventually the castaway creates a secure storehouse for goods, marks the passing of time with notches on wood, builds furniture and later a boat, returns to the island after a dangerous voyage on sea, invents a source of light for his dwelling, tames animals, and creates clothes from animal skins. Crusoe learns how to obtain and grow food for himself, plan ahead and store

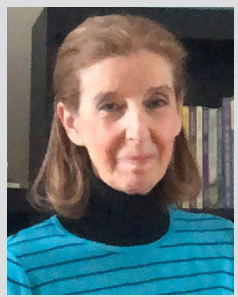

Pauline Dewan is a reference librarian at Wilfrid Laurier University in Ontario, Canada. Co-author of Connecting Children with Classics: A Reader-Centered Approach to Selecting and Promoting Great Literature (2018) and the forthcoming book, Readers' Advisory Guide to Genre Blends for Children and Young Adults, she has also published articles about reading for pleasure. 
provisions, survive natural disasters, fight threats such as cannibals, and cope psychologically with the isolation.

Johann Wyss's The Swiss Family Robinson (1812) and R. M. Ballantyne's The Coral Island (1857) follow this established pattern. The desert island in all these novels acts as a fresh vantage point from which to view society. As the protagonists learn to value nature and devalue money, they become less sure about the advantages of returning home. These survival stories were written during a time when unmapped places still existed in the world, places that readers could easily imagine such adventures taking place in. The threats that the characters face are largely external: natural disasters, wild animals, and enemies identified as pirates, cannibals, or unfriendly natives. The protagonists are European and male; the age is one of empire-building; the world view is colonialist; and the purpose of the novels is religious didacticism.

The Swiss Family Robinson dilutes the excitement of the castaway motif by including an entire castaway family. The air of contrivance in the novel-a father who has expert knowledge of botany and four boys who are perfectly obedient, acquiescent, and brotherly—diminishes the believability of the story. "My great wish," writes the boys' father, "is that young people who read the record of our lives and adventures should learn from it how admirably suited is the peaceful, industrious and pious life of a cheerful, united family to the formation of a strong, pure, and manly character." ${ }^{\prime 4}$ Building their various homes, the family members work tirelessly on additions to them, even building their own library and museum of natural history. Wyss, in fact, seems less interested in depicting the family's survival and more concerned with the way they amass goods and recreate civilization.

Similarly, Ralph Rover in The Coral Island conveniently washes ashore with two friends. ${ }^{5}$ The tropical climate and abundance of edible plants and other sources of food make the island an idyllic retreat rather than a harrowing experience. Like Robinson Crusoe, Ralph Rover believes it is his duty to convert "heathens" to Christianity. Although the artificiality, didacticism, and imperialism of these novels may be a barrier to child readers today, the core narrative of castaways coping in an unfamiliar environment rescues the texts from oblivion. However, few children read these novels in their original form; abridged editions and media adaptations preserve the parts of the story that children find enjoyable.

Arthur Ransome's Swallows and Amazons series (1930-47) ushers the children's survival story into the twentieth century. While on summer holidays at a farm in the English Lake District, the four Walker children sail to a nearby island and pretend to be explorers. Mother facilitates their adventure by sewing tents, supplying provisions, and visiting them periodically. When a boat with a skull-and-crossbones flag draws near, the Walker children meet the fearless Blackett sisters.

Although the children survive by themselves, mother hovers in the background as a backup. The children play at surviving and the threats are artificial. The appeal of the book is not so much the survival story but the humorous tone of the narrator and the feisty character of Nancy Blackett. Ordering her sister about ("Avast there, Peggy, you goat"6) Nancy takes to heart her role as pirate. These classic survival novels by Defoe, Wyss, Ballantyne, and Ransome were written by and about Europeans. Seeing the potential in this type of story, American novelists have since adapted the genre to the needs and concerns of contemporary children.

\section{Changing Landscapes}

Although the desert island began as the typical locale for survival stories, seven of the ten American novels discussed in this article make use of other isolated and inhospitable environments. Sam Gribley in Jean Craighead George's My Side of the Mountain (1959) escapes from his overcrowded New York apartment to a remote location in the Catskill Mountains. Sam's urban upbringing, which sets him apart from his fictional predecessors, leaves him totally unprepared for survival in the wilderness. When he cannot figure out how to get water into his shelter, he says, "That's how citified I was in those days." ${ }^{\prime}$ Sam learns survival skills in a typically urban way through books borrowed from the New York Public Library. He is supported in his efforts, not by a rural inhabitant or local rustic, but by a college professor who is hiking in the area. Sam's dream is a pastoral one-to be completely self-sufficient, living independent of "electricity, rails, steam, oil, coal, machines, and all those things that can go wrong." ${ }^{8}$

Brian Robeson in Gary Paulsen's Hatchet (1986) is another city boy who knows nothing about wilderness survival and must somehow manage in a remote landscape. What makes the story so compelling is that he does manage; his story is one that today's readers can easily relate to. When a pilot flies Brian into the Canadian bush, the man has a heart attack and dies. Brian survives the crash landing but is physically hurt and psychologically overwhelmed. He makes a series of mistakes because of his lack of knowledge: "City boy, he thought. Oh, you city

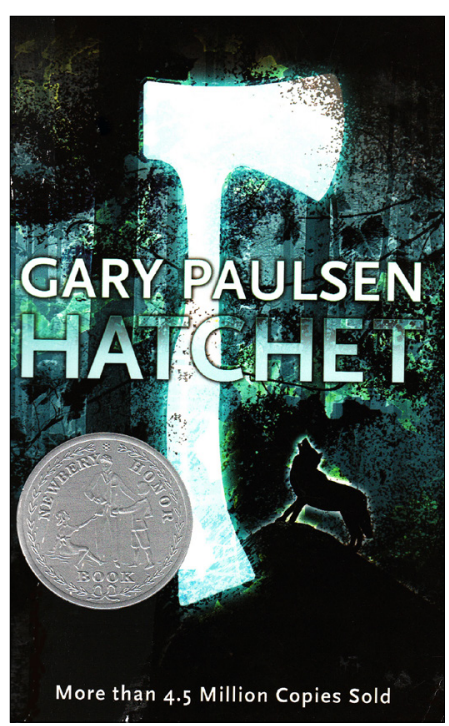
boy with your city ways." 9 The only object that survives the crash is Brian's hatchet, and its cutting action highlights the divisiveness that characterizes his family and his life. It is in the wilderness that Brian also comes to terms with his parent's divorce- "the big split" as he calls it. ${ }^{10}$ Brian helps himself by recalling nature shows on television, and as he slowly makes connections with the world around him, he becomes stronger and more capable. 
While both Sam and Brian leave the city for the wilderness, Aremis Slake in Felice Holman's Slake's Limbo: 121 Days (1974) lives in a city that is depicted as a wilderness. ${ }^{11}$ Slake must develop urban survival skills to manage in the hostile world of New York City. Neglected by his guardian, bullied by his classmates, and chased by authorities, Slake has no friends, parents, siblings, or role models. He descends into the tunnels of the New York subway and lives in an abandoned storage area that is four feet by eight feet. The underground seems to be no different than aboveground, but for the first time Slake possesses his own space, a place where he teaches himself survival skills. Like his Robinsonade predecessors, he learns how to create a shelter for himself, find food, use tools, discover a way to light his dwelling, make friends with an animal, and prepare ahead for times of need. One hundred and twenty-one days later, he emerges aboveground and is ready to cope with the urban wilderness. With just under two-thirds of the American population living in cities, ${ }^{12}$ many children today can identify with the urban background of characters such as Sam, Brian, and Slake.

\section{More Diverse Characters}

The stories of two Sudanese children are juxtaposed in Linda Sue Park's A Long Walk to Water (2010). ${ }^{13}$ Set during the Sudanese Civil War, the novel combines historical narrative with a gripping survival story. When Salva's class is interrupted by the sound of gunfire, his teacher tells the students to run and hide in the bush territory, not to return home. In a mass exodus, the Sudanese villagers are forced to leave their homes and flee their

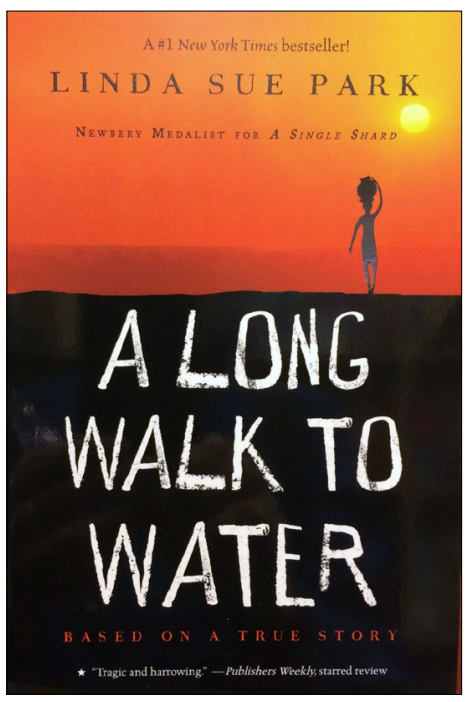
country. Salva is unable

to find his family, but has no choice but to flee south with strangers. Lonely and afraid, he eventually runs into his uncle, a man who helps him escape to Ethiopia. But his uncle is killed and Salva must survive on his own without family or friends. Salva's story alternates with the account of Nya's long, arduous trips to obtain drinking water for her family. Walking back and forth to a pond takes her all day, every day, and becomes increasingly futile once the water is contaminated. The convergence of the two survival stories is poignant and powerful.

Fleeing from a physically abusive father, eleven-year-old Viji and her developmentally delayed sister Rukku, leave for the Indian city of Chennai in Padma Venkatraman's 2019 novel The Bridge Home. With no money and no way of supporting themselves, the girls must learn to survive alone in a big city.
Viji repeatedly tells Rukku a story that ends with the assertion, "We'll be princesses again, Viji and Rukku. . . Always together." 14

But after facing homelessness, starvation, sickness, and predatory adults, Viji eventually gives up on her dreams. It is her sister who gives her the strength to survive. As Viji writes, "All this while, I thought I'd looked after you, but now I see it was often the opposite." ${ }^{15}$ Narrated as letters from one sister to another, this urban survival story is also a psychological exploration of someone coming to terms with profound grief.

Dee Carpenter in Alan Gratz's Allies (2019) knows that surviving D-Day will be extremely difficult. Memories of an uncle who vanished at the hands of Nazis motivate this underage boy to hide his German nationality and fight on the side of the Americans. Landing at Omaha Beach, Dee is completely unprepared for the hellish scenes and impossible choices awaiting him: "To stay in the boat was to die. To push forward was to die. Everything around Dee was suddenly death." ${ }^{16}$ Events are depicted from a variety of perspectives, from people of various nationalities and cultures. The stories of a Canadian Cree Indian, a Jewish American, a British dockworker's son, an Algerian French girl, and an African American medic intersect on this fateful day. The characters face unprecedented horrors, made worse by battle plans that go astray. The traditional desert-island setting of earlier fiction has become a nightmarish beach; fun-filled adventures, momentous historical events, and like-minded companions, a mix of characters from dissimilar backgrounds. Such transformations lend depth and breadth to the traditional survival story.

\section{Threats from Within}

The threats protagonists face in early survival stories-wild animals, cannibals, pirates, enemy tribes, natural disasters-are ones that most children today will rarely, if ever, encounter. Increasingly, authors of survival novels focus on threats from within. The four siblings in Cynthia Voigt's Homecoming (1981) are abandoned by their mother, a mentally ill woman who leaves them in a car in a mall parking lot. With no money, parents, relations except a great-aunt whom they have never met, or adults who can help them, the children are left on their own to survive. They walk from one state to another in a heroic attempt to reach great-aunt Cilla's home. Homelessness and abandonment are key concerns in the novel. "Until she died, Dicey wouldn't expect any place to be home. Home was with Momma-and Momma was in a hospital where the doctors said she'd always stay. There could be no home for the Tillermans." ${ }^{\prime 17}$

Threats from within the family also dominate Watt Key's Alabama Moon (2006). After Moon Blake's father returns from the Vietnam War, he is obsessively suspicious of the government and turns his back on civilization. When he realizes that he is dying from an infection in a broken leg, he tells his son to maintain the same transient lifestyle and to depend on no 
one. Living in a rude dug-out in an Alabama forest, the ten-year-old must bury his father and survive in the wilderness on his own. Never having gone to school, known friends, or even met other people, Moon is truly isolated. To survive, he must also come to terms with the ideas instilled in him by his psychologically traumatized father.

Psychological threats are also the focus of Dan Gemeinhart's Scar Island (2017). ${ }^{18}$ Twelveyear-old Jonathan Grisby is sent to Slabhenge Reformatory School for Troubled Boys - a forbidding, place on a remote island. Run by a sadistic admiral, this former insane asylum is Jonathan's worst nightmare. When the adults who administer the detention center die in a thunderstorm, the boys are left to survive on

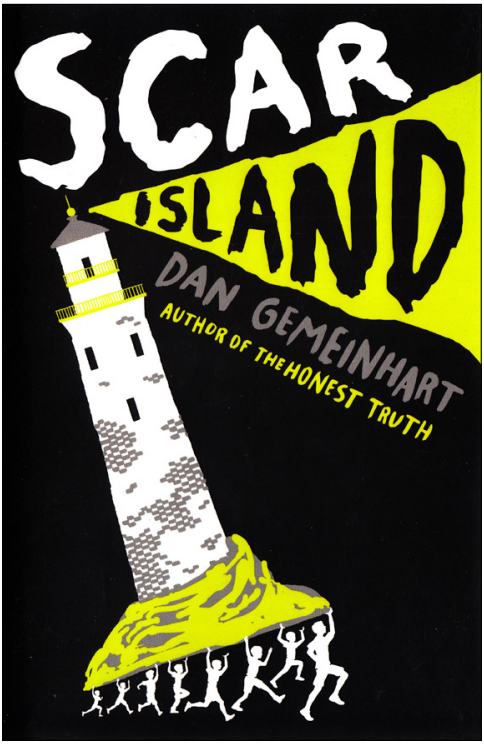
an erosion of childhood. ${ }^{19}$ No longer separate and protected from adulthood, childhood has been increasingly under threat. And it is in America, Cunningham argues, that this breakdown has gone furthest. ${ }^{20}$

Cultural critic Neil Postman also laments the disappearance of childhood, observing that the behavior, language, attitudes, and dress of children are now indistinguishable from that of adults. ${ }^{21}$ The media, he reminds us, provides children with unprecedented access to the adult world, leaving few things secret or hidden from them. Children have become more aware of the dangers of the world and find in the survival novel protagonists who manage in precarious environments. Young readers are keenly aware that dangers can lurk anywhere, can pose threats to anyone their own. Although the threats to the boys' existence are very real, they pale in comparison to the emotional threats that Jonathan faces. To survive, he must learn to cope with the guilt he feels for the death of his sister. Although psychological trauma threatens to engulf him, he learns how to cope on this remote island.

\section{Changing Nature of Childhood}

Hugh Cunningham, emeritus professor of social history, observes that it was in the second half of the twentieth century that the most rapid changes in the conceptualization and experience of childhood began. "The twin forces of the media and of mass consumption," he points out, have contributed to

\section{References}

1. Jon Scieszka, introduction to The Swiss Family Robinson by Johann Wyss (1814; London: Puffin Classics, 2016).

2. Dennis Butts, "Shaping Boyhood: British Empire Builders and Adventurers," in Peter Hunt, ed., International Companion Encyclopedia of Children's Literature, ed. Peter Hunt (London: Routledge, 2004), 340-51.

3. Daniel Defoe, Robinson Crusoe (1719; London: Vintage Books, 2008).

4. Johann Wyss, The Swiss Family Robinson (1814; London: Puffin Classics, 2016), 399.

5. R. M. Ballantyne, The Coral Island (Doylestown, PA: Wildside Press, 2002).

6. Arthur Ransome, Swallows and Amazons (1930; London: Red Fox, 2001), 122.

7. Jean Craighead George, My Side of the Mountain (1959; New York: Puffin, 2004), 34.

8. George, My Side of the Mountain, 165.

9. Gary Paulsen, Hatchet (1987; New York: Simon Pulse, 2004), 95.

10. Paulsen, Hatchet, 6. (not just to white males), and can emerge from both within and without.

Scholars Paula Fass, Steven Mintz, and Stephen Lassonde, each argue that the rapidity with which American family patterns have changed since mid-twentieth century has left parents anxious and hovering-eager to circumscribe their children's behavior and geographic boundaries. ${ }^{22}$

The protagonists in survival novels provide children with a model of coping that goes beyond retreat. By offering a vicarious experience that reflects not just the threats of their world, but also a successful negotiation of them, the survival genre provides children with a much-needed sense of agency. \&

11. Felice Holman, Slake's Limbo: 121 Days (New York: Aladdin, 1974).

12. United States Census Bureau, "U.S. Cities are Home to 62.7 Percent of the U. S. Population, but Comprise Just 3.5 Percent of Land Area," March 4, 2015, www.census.gov /newsroom/press-releases/2015/cb15-33.html.

13. Linda Sue Park, A Long Walk to Water (Boston: Houghton Mifflin Harcourt, 2010).

14. Padma Venkatraman, The Bridge Home (New York: Nancy Paulsen, 2019), chap. 8.

15. Venkatraman, The Bridge Home, chap. 44.

16. Alan Gratz, Allies (Scholastic: New York, 2019), 95.

17. Cynthia Voigt, Homecoming (1981; New York: Simon \& Schuster, 2012), 205.

18. Dan Gemeinhart, Scar Island (New York: Scholastic, 2017).

19. Hugh Cunningham, Children and Childhood in Western Society Since 1500 (London: Routledge Taylor \& Francis, 2005), 172.

20. Cunningham, Children and Childhood in Western Society Since 1500, 189. 
21. Neil Postman, The Disappearance of Childhood (New York: Vintage Books, 1994).

22. Paula S. Fass, The End of American Childhood: A History of Parenting from Life on the Frontier to the Managed Child (Princeton: Princeton University Press, 2016); Paula S. Fass, "The Child-Centered Family? New Rules in Postwar America," in Reinventing Childhood after World War II, eds. Paula S. Fass and Michael Grossberg (Philadelphia: University of Pennsylvania Press, 2012), 1-18; Steven Mintz, “The Changing Face of Children's Culture," in Reinventing Childhood, eds. Fass and Grossberg, 38-50; Stephen Lassonde, "Ten is the New Fourteen: Age Compression and 'Real' Childhood," in Reinventing Childhood, eds. Fass and Grossberg, 51-67. 